\title{
Faces e metamorfoses do poder: uma sociografia dos ministros da educação no Portugal democrático
}

Pedro Abrantes'

Cristina Roldão"

I- Universidade Aberta \& Centro de Investigação e Estudos de Sociologia do ISCTE-IUL, Lisboa, Portugal. Contato: pedro.abrantes@iscte.pt II- Centro de Investigação e Estudos de Sociologia do ISCTE-IUL, Lisboa, Portugal.

Contato: cristinarolda01@gmail.com

\section{Resumo}

0 presente artigo caracteriza o perfil e a trajetória social dos 27 agentes que ocuparam o cargo de ministro da Educação em Portugal, desde a revolução democrática de 1974. Busca-se, com este estudo, contribuir para a análise dos grupos, interesses e ideologias que têm governado o sistema educativo no país, nas últimas décadas. Partimos de um quadro teórico em que se cruzam os estudos a respeito das elites políticas com as pesquisas sobre políticas educativas. Após um debate acerca da volatilidade do cargo, a análise centra-se na compreensão de um padrão observado: a larga maioria dos ministros são homens, nascidos em Lisboa, formados em certas escolas e cursos, com mestrado ou doutorado. Em geral, apresentam-se como independentes, têm carreiras ligadas à docência universitária, à administração pública e, em alguns casos, também à administração de empresas e fundações. É possível, ainda assim, observar mudanças ao longo das últimas décadas, nomeadamente, quanto à área de formação: os historiadores e filósofos do período revolucionário foram substituídos por engenheiros, nos anos 1980 e 1990, e, mais recentemente, por economistas e sociólogos. A formação pós-graduada no estrangeiro, sobretudo na Inglaterra e nos Estados Unidos, também consiste em um recurso importante. Conclui-se que, apesar das mudanças geradas pelos processos democráticos, os ministros da Educação mantiveram um perfil muito específico, buscando conciliar as elites político-econômica e cultural-intelectual, mas mantendo a distinção (e tensão) relativamente ao campo educativo e aos seus agentes, em particular, aos professores do ensino básico e secundário.

\section{Palavras-chave}

Elite política - Governo - Democracia - Sistema educativo. 


\title{
Faces and metamorphoses of power: a sociography of the Portuguese ministers of education in the democratic era
}

Pedro Abrantes

Cristina Roldão"

\begin{abstract}
This article analyzes the profiles and social pathways of the 27 people who occupied the position of Minister of Education from the 1974 democratic revolution onwards as a way of exploring the groups, interests and ideologies governing the education system. It is based on a theoretical framework that combines research into political elites and education policies. After a discussion of the volatility of the position, our analysis focuses on the pattern found. The vast majority of the ministers of education have been men, born in Lisbon, educated in different schools and disciplinary fields, and have held a master's degree or PhD. Furthermore, most of them introduced themselves as independents and their occupations included university professors and managers, usually in the civil service but also with private companies or foundations in some cases. Nonetheless, there have been some shifts in recent decades, especially in their field of studies: historians and philosophers from the revolutionary years were replaced by ministers with degrees in engineering in the 1980s and 90s, and more recently by economists and sociologists. Graduate studies abroad, especially in England and in United States, have been an important resource. In the conclusions, we argue that, despite the changes made by democratic procedures, ministers of education have preserved a very specific profile, as a way of balancing political-economic and culturalintellectual elites, on the one hand, while maintaining a distinction (and tension) towards the compulsory and high-school education staff, on the other.
\end{abstract}

\section{Keywords}

Elite - Politics - Government - Democracy - Educational system.

I- Universidade Aberta \& Centro de Investigação e Estudos de Sociologia do ISCTE-IUL, Lisboa, Portugal. Contato: pedro.abrantes@iscte.pt II- Centro de Investigação e Estudos de Sociologia do ISCTE-IUL, Lisboa, Portugal.

Contato: cristinarolda01@gmail.com 
0 presente artigo caracteriza o perfil e a trajetória social dos 27 ministros da Educação de Portugal, entre 1974 e 2012, com base num conjunto de indicadores sociológicos, enquanto contribuição para a análise dos grupos, interesses e ideologias que têm sido dominantes na definição das políticas educativas. Apesar do interesse da pesquisa educativa recente por conceitos como o poder, a política e a democracia, raramente se têm estudado os atores sociais nomeados para liderar as políticas educativas. ${ }^{1}$

0 artigo primeiramente apresenta a fundamentação teórica do estudo, colocando em diálogo contributos de duas linhas de investigação: uma sobre a formação das elites e, em particular, das elites políticas; e outra que versa sobre políticas educativas e a estruturação dos sistemas de ensino. Após uma breve apresentação do modelo de análise e da metodologia, discutem-se os principais resultados do estudo, em cinco eixos: período de permanência no cargo; sexo e origem social; estudos universitários; relação com os partidos; e trajetórias profissionais.

\section{Elites, política e educação}

0 estudo das elites tem uma longa tradição na sociologia e na ciência política. Relembre-se a influência das teorias clássicas, de autores como Pareto, Mosca e Michels a respeito da existência, em todas as sociedades, de elites que dirigem as massas, enquanto procuram conservar a sua posição distintiva (BOLÍVAR MEZA, 2002). Para isso, buscam renovar-se com as ideias e as pessoas mais aptas de outros meios sociais (circulação das elites). Segundo esses autores, quando não existe tal regeneração, surgem condições propícias para uma mobilização das massas, a largo prazo, originando a substituição da elite, não a sua dissolução. Essas propostas tiveram um profundo impacto no início do século XX, contrariando as visões otimistas, tanto dos

1- Gostaríamos de agradecer à professora Leonor Torres, da Universidade do Minho, pela leitura atenta do artigo e as sugestões para melhorá-lo. apologistas das democracias liberais como dos sistemas comunistas. Embora sem constituir uma teoria geral das elites, também Max Weber (1968) marcou profundamente esse debate com as suas reflexões a respeito da formação do Estado, da burocracia e dos mecanismos de poder e autoridade. Se o autor apresenta uma visão relativamente aberta e multidimensional do poder nas sociedades modernas, apoiado na sua conhecida diferenciação de classes (econômicas), status (social) e partidos (política), reconhece também poderosos mecanismos de fechamento social que acionam os grupos, no sentido de preservar a sua posição privilegiada.

Nos anos 1950, Wright Mills (1959) apoia-se nessas teorias clássicas para fundamentar o seu estudo acerca da elite de poder norte-americana. 0 autor critica as perspectivas pluralistas, mostrando as intensas interligações e sobreposições entre as elites econômica, política, intelectual e militar. Uma hierarquia institucional, interesses e objetivos comuns, bem como uma unidade psicológica e social - formada pela participação duradoura nos mesmos círculos sociais - asseguram essa integração de várias fações numa mesma elite, bem como o seu relativo fechamento com relação aos restantes grupos sociais.

Nessa linha, importa considerar os trabalhos que Pierre Bourdieu desenvolveu acerca da sociedade francesa, entre os anos 1960 e 1990. Na sua obra dedicada à formação das elites, Bourdieu (1989) coloca a tônica na forma como o Estado, através do sistema educativo, tende a separar os jovens em diferentes vias de ensino, reservando algumas instituições específicas (as grandes escolas) para a formação de um grupo restrito, privilegiado em conhecimentos, representações e disposições e que ocupará a classe dirigente.

0 autor centra a sua análise nessas escolas, cujas classificações e ordenações permitem produzir um habitus distintivo e um esprit de corps que dão origem a uma elite coesa, solidária entre si e profundamente convencida da sua superioridade e legitimidade, 
segundo princípios meritocráticos, a que designa "a nobreza de estado". Apesar da unidade de estruturas sociais e mentais que tal socialização proporciona, reconhece que a configuração do sistema educativo - resultado de batalhas incessantes, mas demonstrando uma assinalável estabilidade - impõe diferenciações, nomeadamente, entre um espaço de (re)produção da burguesia político-econômica (dominante) e outro de (re)produção da burguesia culturalintelectual (subordinada).

Nota igualmente que, se o acesso a essas escolas depende em larga medida dos capitais econômicos e culturais da família de origem, a existência de "trânsfugas de classe" (como ele) gera habitus clivados, possíveis indutores de metamorfoses nas estruturas de poder. Num seminário que lecionou nos anos 1990, no Collège de France, Bourdieu (2005) analisou ainda a gênese do Estado moderno (francês), na complexa relação entre mecanismos burocráticos e democráticos, sugerindo a emergência de um capital público, objeto de intensas lutas de poder entre facções de uma "minoria com direitos assignados pela possessão quase hereditária” (BOURDIEU, 2005, p. 67) - a tal "nobreza de estado" - que monopoliza os altos cargos públicos e as recompensas a eles associadas.

Não colocando em causa esse quadro teórico, estudos recentes têm apontado tendências emergentes. Em primeiro lugar, vários autores assinalam o processo de formação de elites transnacionais, associado ao processo de globalização e, em particular, ao crescente peso de organizações intergovernamentais, como são o caso da Organização das Nações Unidas - ONU, da Organização para a Cooperação e Desenvolvimento Econômico - OCDE e da União Europeia (HIGHLEY; BURTON, 2006; WAGNER, 2007). Por um lado, essas provocam instabilidade nas elites (e democracias) nacionais; por outro, geram processos de concentração de poder à escala global. Em segundo lugar, as próprias democracias têm vindo a sofrer mutações. Em detrimento das instituições representativas, têm conquistado protagonismo grupos de interesses empresariais, organizações não governamentais e grupos de peritos, além das referidas agências intergovernamentais (BURNS; CARSON, 2002). Em terceiro lugar, alguns autores têm estudado como os agentes e lógicas do mundo financeiro tendem a alterar a composição e o papel das elites, até o momento, sem estabelecer uma "hegemonia totalizante" (SAVAGE; WILLIAMS, 2008).

Ante esse cenário, o caso de Portugal apresenta singularidades que importa ressaltar. Como mostram Costa et al. (2010), apesar dos diferentes regimes políticos, durante o último século, é possível notar a preservação de um restrito número de famílias, com fortes laços entre si e uma concentração muito significativa de poder econômico, em grande medida, pela sua capacidade de manter uma relação privilegiada com o Estado e, em particular, com os seus governantes. O Estado Novo (19261974) estabeleceu um regime protecionista e autoritário, consolidando uma elite política em estreita aliança com a elite econômica (proteção mútua). No período democrático, depois de um breve período revolucionário, os novos governantes - com a chancela das instituições internacionais - restabelecem esse laço, em nome da estabilidade política e econômica, agora fundado em redes de acumulação e de circulação intensa entre altos cargos na administração pública e privada.

Recorrendo à tipologia de Gill (2000), pode-se dizer que a transição para a democracia não terá correspondido nem a processos de “transação entre elites”, nem de "substituição de uma elite por outra”, mas a um terceiro modelo que a autora designa de "desprendimento" (extrication): a classe dirigente recompôs-se, através da aliança de uma facção liberal e progressista do Estado Novo com segmentos (moderados ou, entretanto, convertidos) da resistência, ambos libertando-se das antigas solidariedades e do antagonismo que os caracterizou durante o período revolucionário. 
Ao contrário do que se passou em muitos países europeus durante a década de 50 e 60, em Portugal, os partidos nunca chegaram a ter uma verdadeira ancoragem a estratos e grupos específicos da sociedade civil. Quando se assiste à democratização político-partidária, já a dinâmica de afastamento dos partidos face à sociedade civil estava em marcha, daí que Panebianco (1988) descreva o surgimento dos partidos do arco da governação como resultante principalmente da mobilização de elites e não tanto das suas bases sociais de apoio.

Como nota Lobo (2003), a escolha dos membros do governo parece estar mais dependente do primeiro-ministro indicado do que dos militantes, elites intermédias ou dos órgãos dirigentes dos partidos. Em simultâneo, a autora assinala uma crescente "governamentalização" das elites político-partidárias, expressa na tendência para os membros de órgãos executivos dos partidos mais votados integrarem o governo ou serem deputados. Desde logo, o titular do cargo de primeiro ministro é simultaneamente o dirigente máximo dos partidos no governo (secretário-geral ou presidente do partido). Essa situação pode ser interpretada, como faz Freire (2003): quer como uma crescente partidocracia do recrutamento para o governo e parlamento, que coloca o problema da subalternização da lógica do Estado à lógica dos partidos; quer como uma crescente profissionalização das carreiras políticas, observada como um indicador de modernização e desenvolvimento político, no sentido em que representa uma maior autonomia da esfera política em face de outros subsistemas sociais.

Por seu lado, os estudos sobre os sistemas educativos têm enfatizado que, nas sociedades modernas e democráticas, a sua estruturação se desenrola segundo um modelo de multirregulação, a partir das relações de força (estratégias, conflitos e negociações) entre diferentes grupos, em múltiplos níveis de escala (ARCHER, 1979; PETITAT, 1982; BOWE; BALL, 1992; FERNÁNDEZ ENGUITA, 2007). A esse propósito, ganha expressão uma tensão entre, por um lado, as elites política e econômica e, por outro, os grupos profissionais (de professores, sobretudo), organizados em associações e sindicatos. Outros atores, como a comunidade científica, a comunicação social, organizações de pais, as administrações educativas e locais ou os diretores de escola, tendem a funcionar como mediadores dessas tensões, ganhando protagonismo em certas conjunturas e não deixando de mobilizar estratégias, culturas e agendas próprias (ABRANTES, 2008).

Outros autores têm observado, sobretudo a partir dos anos 1980, uma reconfiguração dos sistemas educativos, segundo as lógicas de mercado, em grande medida segundo os auspícios de poderosas instituições internacionais (ALTMANN, 2002; APPLE, 2004; DALE, 2004; TEODORO; ANÍBAL, 2007). Nesse sentido, assiste-se a uma penetração dos interesses, lógicas e linguagens empresariais no currículo, na gestão escolar, no controle disciplinar e na avaliação dos agentes educativos, a par de políticas que promovem a competição entre escolas e a "livre escolha" das famílias (POPKEWITZ, 1991; 2008; BARROSO, 2005). Outro indicador desse processo é a presença crescente de governantes educativos com formação em economia, algo que também se observa no Brasil (ALMEIDA, 2008) e que acompanha uma dinâmica de recomposição mais geral dos governos em Portugal (ALMEIDA; PINTO, 2006), na Espanha (LINZ; JEREZ; CORZO, 2006) e na Grécia (SOTIROPOULOS; BOURIKOS, 2006), entre outros países.

Note-se que as instituições e redes internacionais há muito tempo desempenham um papel central na formação e afırmação dos governantes educativos, sobretudo em países periféricos, como está bem patente num estudo da biografia de Anísio Teixeira (BITTENCOURT, 2009). Acresce que a ideologia neoliberal não constitui um conjunto unificado e universal de políticas (NÓVOA, 2000). No caso português, considerando um padrão histórico de altas desigualdades sociais e de um campo empresarial, como se referiu, 
pouco expansionista e fortemente dependente do Estado, tais políticas têm adotado, até o momento, uma forma "mitigada", em comparação ao que se tem observado, por exemplo, nos países anglosaxônicos (AFONSO, 1998; LIMA; AFONSO, 2002; BARROSO, 2005). Ainda assim, a atual crise financeira pode precipitar (e acelerar) tendências que já se vinham consolidando. Além disso, convém não esquecer que, tratando-se de um movimento hegemônico, não invalida a existência de outros movimentos, não apenas de resistência mas também de transformação das realidades educativas.

Alguns autores conceituados têm observado, recentemente, sintomas de saturação do modelo neoliberal, até pelos resultados decepcionantes que tem produzido na esfera educativa (e não só), através de uma (re)valorização de programas de ação em torno da educação intercultural, das redes profissionais, do bemestar infantil, da participação da comunidade educativa (HARGREAVES, 2008; WARREN; MAPP, 2011). Em todo o caso, a integração de tais movimentos no plano das políticas educativas permanece limitada, sobretudo em momentos de crise econômica.

\section{Modelo de análise e estratégia metodológica}

No sentido de contribuir para o conhecimento nesse campo, decidimos realizar uma análise sociográfica dos ministros da Educação, em Portugal, desde a revolução de 1974, explorando como as anteriores teorias sobre as elites e as políticas educativas se consubstanciam no perfil e trajetória dos titulares do cargo mais elevado na administração nacional do sistema educativo. Em termos metodológicos, construímos um conjunto de biogramas, entendidos como a identificação, sistematização e comparação de categorias significativas nos trajetos de vida de um conjunto alargado de indivíduos (PUJADAS, 1992).

Para os propósitos da presente pesquisa - e considerando a informação existente em fontes documentais - selecionamos as seguintes variáveis:
- Local e ano de nascimento;

- Sexo;

- Local, instituição e área disciplinar de formação secundária e superior;

- Filiação partidária, ao longo da vida;

- Período e composição do governo em que exerceu o cargo; e

- Inserções profissionais anteriores e posteriores à ocupação do cargo.

0 objetivo desta análise foi a identificação de padrões e regularidades no perfil e trajetórias desses atores, assim como variações significativas, segundo períodos temporais ou orientações político-partidárias. Esta análise pretendeu elucidar alguns aspetos da relação entre elites e política educativa, assim como o modo como esta tem evoluído, ao longo dos quase quarenta anos de democracia portuguesa.

\section{Perfil e trajetória dos Ministros da Educação (1974-2012)}

A análise sociográfica dos perfis e percursos de vida permitiu-nos identificar cinco traços fundamentais, que apresentamos em seguida, e que marcam a complexa relação entre elites, política e educação, no Portugal contemporâneo.

\section{a) A volatilidade do cargo}

Um aspecto que não deixa de pautar essa relação é a existência de 27 pessoas que ocuparam o cargo, ao longo de 38 anos. Mesmo que para isso tenha contribuído a instabilidade do período revolucionário, a média de permanência no cargo durante o período dos governos constitucionais (GC) continua a ser inferior a dois anos (638 dias), sendo que apenas três governantes cumpriram um mandato completo (1987/91; 1995/99; 2005/09) e nenhum superou essa "barreira" (Quadro 1). Essa volatilidade é evidente quando comparada com a duração das carreiras ministeriais da globalidade dos 
ministros. A pesquisa de Almeida e Pinto (2006), para o período entre 1976 e 1999, revela uma maior proporção de mandatos longos $(19,2 \%$ dos ministros teve mandatos de quatro ou mais anos) do que aquela que observamos para os ministros da Educação no mesmo período (15\%). A hipótese da elevada volatilidade desse cargo - devido a um maior escrutínio social, ao peso no orçamento de Estado e consequente concorrência face a outros ministérios, à grande dimensão e forte dinâmica sindicalista da classe profissional, entre outros fatores - surge reforçada das palavras de vários dos ministros da Educação, entrevistados por António Teodoro (2002).
Sendo certo que, em alguns casos, o afastamento do cargo decorreu da demissão do governo, foi frequente também a sua substituição durante a legislatura ( $8^{\circ}$ e $9^{\circ} \mathrm{GC}$ e, por duas vezes, nos $12^{\circ}$ e $13^{\circ} \mathrm{GC}$ ). Será útil lembrar que se trata do ministério que tem a seu cargo o maior número de funcionários públicos e que as mudanças no setor educativo são necessariamente lentas e complexas. Tendo em conta que, a cada mudança de ministro, sucede a substituição de diversos outros titulares de cargos de topo na administração educativa, é patente o enorme desperdício que representa tal instabilidade, não apenas de recursos financeiros, mas também de tempo, competências e confiança, num pequeno país como Portugal.

Quadro 1 - Duração dos mandatos dos ministros da Educação (1974-2011)*

\begin{tabular}{|c|c|c|c|c|c|c|}
\hline & \multicolumn{2}{|c|}{ N. ${ }^{\circ}$ dias } & \multicolumn{4}{|c|}{$\mathrm{N}^{\circ}$ de anos } \\
\hline & Total & Média & $\begin{array}{l}<=1 \text { ano } \\
(<365 \text { dias })\end{array}$ & $\begin{array}{c}1 \text { a } 3 \text { anos } \\
\text { (366-1095 dias) }\end{array}$ & $\begin{array}{c}>3 \text { anos } \\
(>1095 \text { dias })\end{array}$ & Total \\
\hline $\begin{array}{l}\text { Período Revolucionário } \\
\text { (I-VI Governos Provisórios, 1974/76) }\end{array}$ & 799 & 133 & $\begin{array}{c}100,0 \\
(6) \\
\end{array}$ & - & - & $\begin{array}{c}100,0 \\
(6)\end{array}$ \\
\hline $\begin{array}{l}\text { Governos Constitucionais } \\
\text { (I-XVIII, 1976/2011) }\end{array}$ & 12751 & 638 & $\begin{array}{c}65,0 \\
(9)\end{array}$ & $\begin{array}{c}40,0 \\
(8)\end{array}$ & $\begin{array}{c}15,0 \\
(3)\end{array}$ & $\begin{array}{c}100,0 \\
(20)\end{array}$ \\
\hline Global & 13550 & 521 & $\begin{array}{l}57,7 \\
(15)\end{array}$ & $\begin{array}{c}30,8 \\
(8) \\
\end{array}$ & $\begin{array}{c}11,5 \\
(3)\end{array}$ & $\begin{array}{c}100,0 \\
(26)\end{array}$ \\
\hline
\end{tabular}

Fonte: Biogramas dos ministros da Educação 1974-2013.

* Neste cálculo foram apenas considerados os mandatos dos dezoito primeiros governos constitucionais uma vez que o décimo nono ainda se encontrava em funções à data do fecho do artigo.

Essa volatilidade - que, como se viu, não se pode reduzir a períodos revolucionários ou de instabilidade governamental - deve ser entendida pelas dificuldades de integração dos diferentes poderes capazes de influenciar o campo educativo. Destaca-se a incapacidade de encontrar políticas, e políticos, firmados em acordos entre a elite e as massas ou, numa formulação mais rigorosa, entre os interesses da elite político-econômica, da elite cultural-intelectual e dos agentes do campo educativo, nomeadamente, a classe docente, cujos líderes sindicais estabelecem frequentemente contraelites (SAVAGE; WILLIAMS, 2008). A participação de outros grupos, como os pais, os alunos ou as autarquias, pelas suas dificuldades organizacionais, têm desempenhado um papel menos central no campo educativo, ainda que a sua mobilização tenha sido relevante em alguns momentos, influenciando também a decisão de prosseguir as reformas ou, pelo contrário, "reformar" os ministros. Se os conflitos entre os referidos atores coletivos (e, por vezes, no seio de cada um), exacerbados pelos media (ABRANTES, 2008; 2009), afiguram-se frequentemente insanáveis, importa não esquecer que as democracias representativas, em diferentes partes do mundo, têm-se baseado nesse tipo de alianças, ainda que frágeis e temporárias (FREIRE, 2003; HIGHLEY; BURTON, 2006; GILL, 2000).

\section{b) Homens, oriundos das áreas metropolitanas e dos "grandes liceus"}

Apenas quatro das 27 pessoas que ocuparam o cargo desde 1974 são do sexo feminino (Quadro 2). Esse dado não deixa de ser 
significativo, atendendo a que o setor educativo, enquanto área profissional, tem sido ocupado na sua esmagadora maioria por mulheres. Em todo o caso, o fato de três das mulheres terem desempenhado o cargo nos últimos oito anos indicia uma transformação que terá de ser observada nas próximas legislaturas.

No que diz respeito às idades dos titulares quando da sua primeira nomeação, prevalecem claramente os indivíduos de meia idade (41-50 anos), cabendo assinalar que o período do PREC, face ao dos governos constitucionais, teve maior participação de ministros mais jovens. Ainda assim, em ambas as fases, a idade média situa-se nos 48 anos, valor ligeiramente acima daquele observado (46 anos) para a globalidade dos ministros entre 1976 e 1999 (ALMEIDA; PINT0, 2006).

Quadro 2 - Perfil social dos ministros da Educação (1974-2013)

\begin{tabular}{|c|c|c|}
\hline & & $\mathrm{N}^{0}$ de Ministros \\
\hline \multirow{2}{*}{ Sexo } & Masculino & 23 \\
\hline & Feminino & 4 \\
\hline \multirow{3}{*}{ Naturalidade } & Distrito de Lisboa & 16 \\
\hline & Distrito do Porto & 3 \\
\hline & Outros* & 8 \\
\hline \multirow{3}{*}{ Escalão etário } & $<=40$ anos & 5 \\
\hline & $41-50$ anos & 14 \\
\hline & $>=51$ anos & 8 \\
\hline \multirow{13}{*}{$\begin{array}{l}\text { Estabelecimentos de ensino } \\
\text { frequentados no ensino secundário** }\end{array}$} & Liceu Pedro Nunes (1905/06) & 3 \\
\hline & Liceu D. Manuel II / Rodrigues de Freitas (1840/41) & 3 \\
\hline & Liceu Passos Manuel $(1838 / 39)$ & 2 \\
\hline & Liceu D. João de Castro (1828/29) & 2 \\
\hline & Liceu Nacional de Leiria (1851/52) & 2 \\
\hline & Liceu de Oeiras (1952) & 2 \\
\hline & Liceu Gil Vicente $(1914 / 15)$ & 1 \\
\hline & Liceu Maria Amália Vaz de Carvalho (1885/86) & 1 \\
\hline & Liceu de Angra do Heroísmo (1851/52) & 1 \\
\hline & Liceu Nuno Álvares (1851/52) & 1 \\
\hline & Lycée Français Charles Lepierre (privado; 1907) & 1 \\
\hline & Colégio Militar (1803) & 1 \\
\hline & NS (informação indisponível) & 10 \\
\hline
\end{tabular}

Fonte: Biogramas dos ministros da Educação 1974-2013

* Aveiro, Braga, Castelo Branco, Coimbra, Leiria, Portalegre, Santarém e Viseu.

** Os anos letivos referem-se ao ano de início do funcionamento das escolas. (Foram contabilizados tantos liceus quantos aqueles frequentados por cada ministo.

Ainda que as informações recolhidas apontem para uma primazia de meios sociais favorecidos, os dados sociográficos que conseguimos recolher sobre as famílias de origem é exígua, não permitindo extrapolações. Contudo, observando o local de nascimento e residência durante a infância, podemos identificar uma clara prevalência do distrito de Lisboa (16 de 27). Note-se que, nos anos 50 e 60, essa região concentrava apenas cerca de
15\% população, mas a maioria dos recursos econômicos, culturais e políticos, segundo o modelo dual de desenvolvimento que caracterizava o país (SEDAS NUNES, 1964).

Esse padrão parece inclusive acentuar-se, sendo os últimos cinco ministros naturais da região de Lisboa. As escassas exceções vêm de alguns atores provenientes do distrito do Porto e ou de cidades da zona centro (Leiria, Castelo Branco, Tomar, Cantanhede). Não 
existem originários das ilhas, do Algarve ou de Trás-os-Montes. É importante, aliás, referir que essa sobrerrepresentação da capital, apesar de generalizada aos diferentes governos e pastas ministeriais, é particularmente saliente na pasta da educação. Almeida e Pinto (2006), para o período 1976-99, observaram que um terço dos ministros era natural de Lisboa, quando na nossa amostra representam mais de metade dos casos.

Quase todos, entre aqueles para os quais conseguimos obter informação (17), realizaram os seus estudos secundários em cursos científicos ou humanísticos (via orientada para o ensino superior), em certos liceus, designação das escolas públicas com um ensino orientado para o prosseguimento de estudos universitários, antes de 1974 (Quadro 2). É significativo que apenas um ministro é formado num colégio privado, via frequentemente associada à formação das elites, e que nenhum tenha frequentado o ensino técnico-profissional, sendo o caso mais próximo disso a frequência no Colégio Militar.

Os liceus encontram-se entre as escolas públicas mais antigas e prestigiadas do país. Apesar das diferenças de estatuto ( $1^{\text {a }}$ classe $/ 2^{a}$ classe; nacionais / centrais / municipais etc.), existia, durante o Estado Novo, uma grande proximidade entre liceus e elites. Não só os liceus eram poucos, na maior parte localizados em capitais de distrito e no litoral, como eram um elemento de forte distinção local. Eram liderados por reitores nomeados pelo governo, tendo muitos deles (assim como professores) desempenhado posições prestigiadas nas elites política, burocrático-administrativa, econômica e artístico-cultural (NÓVOA et al., 2003; BARROSO, 1995). Do ponto de vista socioeconômico, os alunos que chegavam ao liceu correspondiam a uma minoria que contrastava profundamente, desde logo, com os alunos das escolas comerciais e industriais, mas, sobretudo, com a massa de população ligada à agricultura no interior do país (CRUZEIRO; ANTUNES, 1978; GRÁCIO, 1986).

Os liceus proporcionavam um enquadramento socioeducativo marcante do ponto de vista pessoal, tanto pela homogeneidade social como pela capacidade de penetração e moldagem de diferentes dimensões, internas e externas, da vida dos alunos. A preocupação com a educação integral ganha terreno a partir do início do século XX, destacando-se, entre outras, as atividades relativas às associações escolares e outras formas de ação coletiva de iniciativa estudantil (caixas escolares; sessões culturais; visitas de estudo e excursões; jornais escolares; campeonatos desportivos; grupos corais, de teatro etc.), extintas em 1942, e as atividades extracurriculares de participação obrigatória promovidas pela Mocidade Portuguesa e Mocidade Portuguesa Feminina, que vieram substituir as organizações autônomas geridas pelos alunos (BARROSO, 1995).

0 confinamento social produzido pelos mecanismos de recrutamento das escolas de elite, assim como a capacidade de penetração simbólico-ideológica, contribuíram para uma relativa homogeneização desses grupos e construção de redes sociais intraelites, forjadas numa socialização contínua e prolongada numa fase marcante do desenvolvimento de qualquer indivíduo. Essa rede de relações, assim como a interiorização profunda de um conjunto de códigos comuns, persiste e opera para lá da vida escolar (BOURDIEU, 1989).

\section{c) A primazia de certas universidades (públicas) e áreas de formação}

Todos os ministros da Educação, desde 1974, eram detentores de uma licenciatura e a maioria contava com estudos de mestrado e/ou doutorado, quando exerceram o cargo (Quadro 3). Quando olhamos para o perfil escolar da globalidade dos ministros entre 1976-1999, menos de um terço tinha mestrado ou doutorado (ALMEIDA; PINTO, 2006), quando na população aqui analisada esse é o perfil dominante.

Além disso, exceto no período revolucionário, em que quatro militares ocuparam o cargo de ministro de Educação, a larga maioria (17) permaneceu ligada 
Quadro 3 - Trajetos acadêmicos dos ministros da Educação (1974-2013)

\begin{tabular}{|c|c|c|}
\hline \multirow{3}{*}{ Escolaridade } & Doutoramento & 17 \\
\hline & Mestrado & 7 \\
\hline & Licenciatura & 3 \\
\hline \multirow{7}{*}{$\begin{array}{l}\text { Estabelecimentos de ensino frequentados na } \\
\text { licenciatura }\end{array}$} & Instituto Superior Técnico - UTL & 6 \\
\hline & Instituto Superior de Economia e Gestão (Ex-ISCEF) - UTL & 3 \\
\hline & Faculdade de Letras - UL & 3 \\
\hline & Faculdade de Ciências - UC & 3 \\
\hline & Faculdade de Direito - UL & 2 \\
\hline & Instituto Superior de Engenharia do Porto & 2 \\
\hline & Outros & 7 \\
\hline \multirow{8}{*}{ Área de formação da licenciatura } & Engenharias (Química, Civil, Mecânica, Hidráulica) & 10 \\
\hline & Ciências Fisico-Químicas & 3 \\
\hline & Farmácia & 1 \\
\hline & Ciências Histórico-filosóficas / Filosofia / História & 4 \\
\hline & Economia & 4 \\
\hline & Ciências Jurídicas / Direito & 3 \\
\hline & Sociologia & 1 \\
\hline & Militar & 1 \\
\hline \multirow{5}{*}{$\begin{array}{l}\text { Estabelecimentos de ensino frequentados no } \\
\text { mestrado/ doutoramento }\end{array}$} & Estabelecimentos de ensino internacionais & 11 \\
\hline & Universidade Nova de Lisboa & 3 \\
\hline & Instituto Superior de Ciências do Trabalho e da Empresa & 2 \\
\hline & Instituto Superior de Engenharia do Porto & 2 \\
\hline & Outros estabelecimentos de ensino nacionais & 3 \\
\hline
\end{tabular}

Fonte: Biogramas dos Ministros da Educação 1974-2013.

às universidades, sendo a docência e/ou a investigação uma das suas principais ocupações laborais, ao longo da vida. Alguns foram inclusive reitores das respectivas instituições (3), antes da sua integração no governo. Fica patente que a legitimidade do governo educativo não dispensa a preservação da forma piramidal (simbólica) do sistema educativo, encontrando-se no topo a academia e conferindo um lugar subordinado ao ensino orientado para a prática, dos institutos politécnicos e das escolas técnicas.

Apenas algumas universidades
estão presentes e, dentro delas, certas áreas disciplinares. Com relação à licenciatura, podemos observar uma clara prevalência das licenciaturas em universidades públicas (26), em particular, da Universidade Técnica de Lisboa (9) e, dentro desta, do Instituto Superior Técnico (IST) (6) - tão mais surpreendente quando não existe, nessa instituição, investigação ou docência na área da educação. Assim, dez ministros foram licenciados em Engenharia, com alguma primazia para a engenharia química (4), número ao qual devemos acrescentar três que se licenciaram em ciências físico-químicas e um em farmácia. Uma nota evidente a fazer é a ruptura drástica com o perfil de formação dos ministros da Educação durante o Estado Novo (BRAGA, 2010), em que a frequência das Faculdades de Direito das Universidades de Coimbra e de Lisboa era predominante, assemelhando-se às grandes écoles francesas, pela importância que revelavam nos processos de recrutamento da elite política (BOURDIEU, 1989; PINTO, 2000).

É possível identificar três períodos: um primeiro em que se alternaram militares e filósofos-historiadores (1974-78), um segundo quase totalmente dominado por engenheiros (1978-1999), aspecto que vai ao encontro ao seu aumento entre a generalidade dos titulares ao cargo de ministro e, finalmente, um terceiro com formações mais diversas, mas com vantagem para economistas e sociólogos, 
sendo que, no caso dos primeiros, corresponde a uma dinâmica transversal a diferentes pastas ministeriais (ALMEIDA; PINTO, 2006).

Com relação às pós-graduações, sente-se uma presença maior de instituições internacionais (11 em 21): francesas, nos anos 1970, inglesas e norte-americanas desde os anos 1980. Apesar de alguns dos ministros terem experiência de trabalho no domínio educativo antes da entrada no cargo, nenhum dos 27 foi licenciado em educação ou pedagogia e apenas dois realizaram pós-graduações na área.

Com paralelismos ao observado por Bourdieu (1989 e 2005), na França, a nomeação para o cargo de ministro da Educação parece ser favorecida por uma longa socialização em certas escolas (públicas), do ensino secundário e superior, produtoras de redes, disposições e capitais distintivos. 0 IST é um caso paradigmático. Sendo mais recentes e menos reconhecidas (ou mesmo um handicap) as formações em educação e em administração pública, nos círculos de poder, ganhou preponderância a formação em letras, no período revolucionário, em engenharia, nas últimas duas décadas do século $\mathrm{XX}$ e, mais recentemente, em economia e sociologia. Refletindo mudanças nas relações de poder entre áreas do saber, em particular, sobre o campo educativo, e mantendo as ciências da educação numa posição subalterna, essas flutuações não deixam de corresponder a diferentes estratégias das elites para o governo da educação (e, em particular, dos professores). A tendência internacional (POPKEWITZ, 1991; ALMEIDA, 2008) tem identificado, grosso modo, uma sequência de períodos de orientação humanista, tecnocrática e economicista.

Além disso, a frequência dos estudos de pós-graduação no estrangeiro mostra como esses constituem capitais importantes no seio de estratégias de internacionalização, cosmopolitismo e isomorfismo institucional que marcaram as políticas educativas, nas décadas mais recentes (POPKEWITZ, 1991; 2008; NÓVOA, 2000; DALE, 2004; TEODORO;
ANÍBAL, 2007). A própria transferência de uma esfera de influência francófona para outra anglo-saxônica é representativa das metamorfoses nas relações (globais) de poder, entre os campos político e educativo, tanto mais que é concomitante com um processo de aprofundamento da integração europeia, no qual seria de esperar um maior peso dos sistemas do centro do continente, mas não tanto do Reino Unido e, menos ainda, dos Estados Unidos. 0 trabalho recente de Bittencourt (2009) mostra como a formação pós-graduada em certas instituições internacionais, particularmente influentes em certas épocas e regiões, pode ser decisiva no acesso a lugares de topo no governo educativo, sobretudo em países da periferia do sistema-mundo, conferindo uma legitimidade (interna e externa) que resulta tanto da socialização como da rede de relações em que se integram os agentes e dos recursos que podem daí advir.

\section{d) A preponderância dos centro-direita e dos independentes}

Oito dos ministros estavam filiados ao Partido Social Democrata (PSD), cinco ao Partido Socialista (PS), sendo os demais considerados independentes, por não assumirem o seu vínculo partidário ou por não ser conhecida a sua participação em cargos ou militância partidária, à época (Quadro 4). Essa primazia do PSD (partido habitualmente situado no centro-direita do espectro político-ideológico) explica-se não apenas por ser o partido que, entre 1974 e 2012, mais tempo esteve no governo mas também porque nas coligações governamentais, quer com o PS quer com o CDS-PP, fez prevalecer o seu domínio sobre a educação.

Em todo o caso, não deixa de ser significativo o número de independentes a ocuparem o cargo (14), a larga maioria com uma posição dominante no mundo universitário, refletindo uma estratégia de amenizar a tensão entre elites e massas ou, com mais rigor, entre elite político-econômica, 
elite cultural-intelectual e classe profissional (professores), através da nomeação de ministros como mediadores, com uma posição reconhecida nos três campos e dominando as suas diferentes estruturas, lógicas $\mathrm{e}$ linguagens. Os engenheiros do IST parecem ter ocupado esse lugar, pelo menos, durante os anos 1980 e 1990, associados a uma política de tônica modernizadora e tecnocrática (ALVES; CANÁRIO, 2004).

Quadro 4 - Duração dos mandatos dos ministros da Educação, segundo filiação partidária, duração dos governos e orientação político-ideológica (1974-2011)*

\begin{tabular}{|c|c|c|c|c|c|c|c|}
\hline & & \multicolumn{2}{|c|}{ N. ${ }^{\circ}$ dias } & \multicolumn{4}{|c|}{$\mathrm{N}^{\circ}$ de anos } \\
\hline & & Total & Média & $\begin{array}{l}<=1 \text { ano } \\
(<365 \text { dias })\end{array}$ & $\begin{array}{c}1 \text { a } 3 \text { anos } \\
\text { (366-1095 dias) }\end{array}$ & $\begin{array}{c}>3 \text { anos } \\
\text { (>1095 dias) }\end{array}$ & Total \\
\hline \multirow{4}{*}{$\begin{array}{l}\text { Filiação partidária do titular do cargo } \\
\text { de ministro }\end{array}$} & PSD & 5037 & 630 & 25 (2) & 75 (6) & - & $100(8)$ \\
\hline & PS & 3119 & 624 & $60(3)$ & $20(1)$ & $20(1)$ & $100(5)$ \\
\hline & "Independentes" & 5393 & 415 & $76,9(10)$ & $7,7(1)$ & $15,4(2)$ & $100(13)$ \\
\hline & Total & 13549 & 521 & $57,7(15)$ & 30,8 (8) & $11,5(3)$ & $100(26)$ \\
\hline \multirow{5}{*}{$\begin{array}{l}\text { Orientações político-ideológicas dos } \\
\text { partidos no governo** (1974-2011) }\end{array}$} & Centro-Direita & 5967 & 746 & $25(2)$ & $50(4)$ & $25(2)$ & $100(8)$ \\
\hline & Centro-Esquerda & 5192 & 1038 & $20(1)$ & $40(2)$ & $40(2)$ & $100(5)$ \\
\hline & Esquerda & 799 & 133 & $100(6)$ & - & - & $100(6)$ \\
\hline & Heterogêneo & 1591 & 318 & $80(4)$ & $20(1)$ & - & $100(5)$ \\
\hline & Total & 13549 & 565 & $54(13)$ & $29(7)$ & $17(4)$ & $100(24)$ \\
\hline
\end{tabular}

Fonte: Biogramas dos Ministros da Educação 1974-2013.

* Neste cálculo, foram apenas considerados os mandatos dos dezoito primeiros governos constitucionais, uma vez que o décimo nono ainda se encontrava em funções à data do encerramento do artigo.

** Neste caso, foi tida em conta a duração dos governos e não dos mandatos dos ministros da Educação.

O elevado número de independentes e a pouca expressão dos parlamentares ou dirigentes partidários no recrutamento ministerial é um traço transversal ao governo português desde 1974, independentemente do tipo de governo (maioria absoluta, relativa, coligações, iniciativa presidencial etc.) e da sua orientação ideológica. Essa característica contrasta com outros países europeus. Pinto e Almeida (2009) avançam algumas hipóteses interligadas para a explicação dessa peculiaridade. Vários desses ministros, antes de ocuparem o cargo, trabalharam em gabinetes ministeriais ou em funções de dirigentes da administração pública, pelo que lhes é reconhecida legitimidade técnica e pericial, recurso importante face à complexidade introduzida pelo envolvimento nas estruturas internacionais. Segundo os mesmos autores, quando existem remodelações do governo, os ministros independentes tendem a ser mantidos. Outro fator avançado prende-se com a necessidade de abertura sentida pelos partidos dada a fraca penetração na sociedade civil e o afastamento da vida partidária de muitos profissionais de topo ou altamente qualificados. Um terceiro fator prende-se com a crescente personalização da política eleitoral e a presidencialização dos governos nas democracias modernas, o que contribui para uma concentração de poder e aumento da autonomia dos primeiros-ministros em vários aspectos, designadamente na escolha dos titulares para os cargos ministeriais.

Essas hipóteses encontram reforço quando analisamos o perfil dos ministros da Educação dos últimos 40 anos. É interessante notar como a trajetória dos independentes, em geral, inclui uma larga experiência (de gestão) em universidades e/ou na administração pública, mas reduzida (ou nula) nos ensinos básico e 
secundário (somente dois) ou em organizações (profissionais e da sociedade civil) dedicadas à educação. Nesse sentido, poderão estar mais à vontade para mediar as relações entre elites político-econômica e cultural-intelectual, mas dificilmente a relação entre essas e os agentes escolares, em particular, aqueles que se integram no ensino básico e secundário. É provável que esse traço contribua para que a classe docente sinta frequentemente que, em vez de uma mediação, os ministros da Educação representam políticas de imposição, por parte das elites, o que tem reforçado a contestação e, logo, a volatilidade do cargo.

e) O fluxo incessante entre universidades, administração pública, fundações e empresas

Analisando as ocupações socioprofissionais ao longo da vida, é possível constatar que a maioria dos ministros da Educação não revela uma carreira política longa, entendendo a política representativa no seu sentido estrito (cargos de governação, em parlamentos, autarquias ou direção de partidos). Como se referiu, muitos deles apresentam-se, profissionalmente, como docentes universitários, sendo, aliás, esse o perfil dominante do recrutamento ministerial (ALMEIDA; PINTO, 2006). Todavia, observando com mais detalhe, quase todos ocuparam cargos de gestão e administração, em diferentes organismos públicos e privados, para além dos nove que exerceram, antes e/ou depois da passagem por esse ministério, funções governativas em outros ministérios.

Em termos da trajetória anterior, além da já referida experiência na direção de (certas) faculdades e universidades, é possível identificar duas organizações centrais na formação de vários ministros da Educação. Por um lado, alguns dos titulares dessa pasta no período democrático colaboraram, durante os anos finais do Estado Novo, com o Grupo de Avaliação e Planeamento da Ação Educativa (GEPAE) do então Ministério da Educação Nacional. Se bem que esse grupo defendeu um conjunto de reformas progressistas para a educação portuguesa, enfrentando as alas mais conservadoras, não deixou de participar no regime autoritário imposto pelo Estado Novo (ABRANTES, 2008). A presença desse grupo dá razão à tese, referida anteriormente, do desprendimento como modelo de transição para a democracia (GILL, 2000). Por outro lado, alguns desempenharam funções na Fundação Calouste Gulbenkian. Sendo uma organização privada sem fins lucrativos, dedicada a diferentes áreas, tem tido um papel importante na estruturação do campo educativo, financiando programas, projetos e investigadores. Nesse sentido, a sua participação encontra-se próxima do modelo de democracia orgânica, observado noutros países europeus e nos Estados Unidos, em que os partidos buscam apoio e legitimidade em poderosas organizações não governamentais, pela sua estabilidade, (relativa) neutralidade, capital técnico e relações externas (BURNS; CARSON, 2002; SAVAGE; WILLIAMS, 2008).

Além disso, a passagem pelo cargo tem um impacto nas carreiras profissionais. Como já mencionado, antes de serem nomeados ministros, muitos ocuparam posições técnicas ou de direção em organismos públicos. Depois de exercer funções dentro do governo, vários desses atores tornaram-se administradores de fundações e empresas, tanto públicas como privadas. Essa transição representa não apenas a ascensão de um novo grupo social na sociedade portuguesa, com uma capacidade enorme de concentração de poderes materiais e simbólicos (os administradores), associada a uma diluição das fronteiras entre o setor público e privado, mas também o peso das funções de governo enquanto porta de acesso de uma fração favorecida dos técnicos superiores e quadros dirigentes a esse grupo, devido ao capital público acumulado, como, aliás, descrevem Costa et al. (2010). Abre-se, dessa forma, caminho a novas estratégias de concentração de poder, através dos laços estreitos entre as elites política e econômica, nacional e internacional. 


\section{Notas conclusivas}

A análise dos perfis e trajetórias dos ministros da Educação de Portugal, desde a revolução de 1974, permitiu-nos encontrar certos padrões com relação ao sexo, à idade, à origem territorial, às escolas e áreas de formação, bem como às ocupações profissionais. Se, em traços largos, esses padrões confirmam as teorias existentes sobre os critérios restritos na formação e seleção das elites políticas (a "nobreza de estado"), o campo da educação em Portugal apresenta especificidades. É significativa a preponderância de figuras que se apresentam como "independentes", circulando entre o mundo universitário e a administração (pública e privada), especializados nas áreas de engenharia e, mais recentemente, de economia, mas com escassa formação em educação (ou pedagogia) e reduzida experiência de trabalho com os níveis de ensino básico e secundário.

Ao longo da coleta de dados, verificaramse dificuldades em obter informação comparável a respeito dos 27 ministros, sobretudo porque o volume, o tipo de informação disponível e o seu nível de detalhe variam muito entre casos, mesmo tratando-se de fontes de informação públicas que, à partida, deveriam estabelecer critérios homogêneos na recolha de informação. Constituindo uma limitante do refinamento da análise, essa constatação não deixa de ser um resultado relevante da pesquisa, indiciando processos recorrentes de ocultação identitária que permitem estratégias flexíveis e sofisticadas de reconstrução dos "modos de apresentação do eu” (GOFFMAN, 1993), consoante os contextos e conjunturas. Existem duas dimensões em que a ocultação é sobejamente visível: as origens sociais dos titulares do cargo e o seu envolvimento político-partidário. Esta última permite, aliás, a construção social dessa figura sui generis do independente, mascarando a sua atuação propriamente política sob um perfil de legitimidade técnica e, em particular, as suas relações longas e de dependência (mesmo que informais) com círculos de poder, de aspecto mais ou menos partidário.

Várias questões ficam por responder e podem alimentar futuras explorações. Uma delas tem precisamente a ver com os lugares de classe dos pais e avós. Outra, com as relações que estabelecem esses atores com os partidos políticos e com outras redes de poder. Alargando o alcance da análise, será importante observar o perfil e trajetória de outros titulares importantes de cargos do governo educativo, como é o caso dos secretários de estado, dos diretores-gerais e dos diretores regionais. Será também interessante comparar com os perfis e trajetórias dos governantes educativos em outros países, de modo a observar tendências internacionais e singularidades portuguesas.

Não negamos que, entre as atribuições de ministro, nas democracias liberais contemporâneas, tendem a prevalecer frequentemente as suas dimensões de representação e de mediação, ante um vasto leque de grupos de interesse, sendo variável o seu peso efetivo na definição das políticas educativas. Em todo o caso, na medida em que essa representação e mediação também dificilmente são imparciais, o conhecimento a respeito do perfil e da trajetória dos ministros não deixa de ser relevante para a compreensão das orientações políticas que têm regido o campo educativo e, num nível mais profundo, das relações de forças que o têm estruturado.

\section{Referências}

ABRANTES, Pedro. Os muros da escola: distâncias e transições entre ciclos de ensino. Tese (Doutorado em Sociologia) - ISCTEIUL, Lisboa, 2008.

ABRANTES, Pedro. Os guardiões do templo: a imprensa generalista e a imposição de uma agenda educativa. Educação, Sociedade e Culturas, Porto, n. 27, p. 127-144, 2009.

AFONSO, Almerindo Janela. Políticas educativas e avaliação educacional. Braga, Universidade do Minho, 1998. 
ALMEIDA, Ana Maria F. 0 assalto à educação pelos economistas. Tempo Social, São Paulo, v. 20, n. 1, p. 163-178, 2008.

ALMEIDA, Pedro T.; PINTO, António C. Os ministros portugueses, 1851-1999: perfil social e carreira política. In: ALMEIDA, Pedro T.; PINTO, António C.; BERMEO, Nancy (Eds.). Quem governa a Europa do Sul?: 0 recrutamento ministerial, 1850-2000. Lisboa: Imprensa de Ciências Sociais, 2006. p. 19-58.

ALTMANN, Helena. Influência do Banco Mundial no projeto educacional brasileiro. Educação e Pesquisa, São Paulo, v. 28, n. 1, p. 77-89, 2002.

ALVES, Natália; CANÁRIO, Rui. Escola e exclusão social: das promessas às incertezas. Análise Social, Lisboa, v. 38, n. 169, p. 981-1010, 2004.

APPLE, Michael. Creating difference: neo-liberalism, neo-conservatism and the politics of educational reform. Educational Policy, V. 18, n. 1, p. 12-44, 2004.

ARCHER, Margaret. Social origins of educational systems. Londres: Sage, 1979.

BARROSO, João. 0s liceus: organização pedagógica e administração (1836-1960). Lisboa: JNICT/FCG, 1995.

BARROSO, João. 0 estado, a educação e a regulação das políticas públicas. Educação e Sociedade, Campinas, v. 26, n. 92, p. 725-751, 2005.

BITTENCOURT, Agueda B. Trajetória de herdeiro entre dois projetos políticos. Educação e Pesquisa, São Paulo, v. 35, n. 1, p. 99-112, 2009.

BOLÍVAR MEZA, Rosendo. La teoría de las elites en Pareto, Mosca y Michels. Iztapalapa, México DF, v. 23, n. 52, p. 386-407, 2002.

BOURDIEU, Pierre. La noblesse d'état: grandes écoles et esprit de corps. Paris: Les Éditions de Minuit, 1989.

BOURDIEU, Pierre. De la casa del rey a la razón de Estado: un modelo de la génesis del campo burocrático. In: WACQUANT, Loic (Ed.). El misterio del ministerio: Pierre Bourdieu y la política democrática. Barcelona: Gedisa, 2005. p. 43-69.

BOWE, Richard; BALL, Stephen. Reforming education and changing schools. Londres: Routledge, 1992.

BRAGA, Paulo D. Os ministros da educação nacional (1936-1974): sociologia de uma função. Revista Lusófona de Educação, Lisboa, n. 16, p. 23-38, 2010.

BURNS, Tom; CARSON, Marcus. European union, neo-corporatist, and pluralist governance arrangements: lobbying and policy-making patterns in a comparative perspective. International Journal of Regulation and Governance, v. 2, n. 2, p. 129-175, 2002.

COSTA, Jorge et al. Os donos de Portugal: cem anos de poder económico. Porto: Afrontamento, 2010.

CRUZEIRO, Maria Eduarda; ANTUNES, Marinho. Ensino Secundário: duas populações, duas escolas. Análise Social, Lisboa, v. 14, n. 55, p. 443-502, 1978.

DALE, Roger. Globalização e educação: demonstrando a existência de uma "cultura educacional mundial comum" ou localizando a uma "agenda globalmente estruturada para a educação"? Educação e Sociedade, Campinas, v. 25, n. 87, p. 423-460, 2004.

FERNÁNDEZ ENGUITA, Mariano. Educação e transformação social. Mangualde: Pedago, 2007.

FREIRE, André. Recrutamento parlamentar e reforma das instituições. In: PINTO, António C.; FREIRE, André (Eds.). Elites, sociedade e mudança política. Oeiras: Celta, 2003. p.181-216.

GILL, Graeme J. The dynamics of democratization: elites, civil society, and the transition process. New York: St. Martin's Press, 2000.

GOFFMAN, Erving. A apresentação do eu na vida de todos os dias. Lisboa: Relógio d’Água, 1993.

GRÁCIO, Sérgio. Política educativa como tecnologia social: as reformas do ensino técnico de 1948 e 1983. Lisboa: Horizonte, 1986.

HARGREAVES, Andy. The coming of post-standardization: three weddings and a funeral. In: SUGRUE, Ciaran (Ed.). The future of educational change: international perspectives. Oxon: Routledge, 2008. p. 14-33.

HIGLEY, John; BURTON, Michael. Elite foundations of liberal democracy. Lanham: Rowman \& Littlefield, 2006.

LIMA, Licíno; AFONSO, Almerindo J. Reformas da educação pública: democratização, modernização, neoliberalismo. Porto: Afrontamento, 2002. 
LINZ, Juan; JEREZ, Miguel; CORZO, Susana. Ministros e regimes em Espanha: da primeira à segunda restauração. In: ALMEIDA, Pedro T.; PINTO, António C.; BERMEO, Nancy (Eds.). Quem governa a Europa do Sul? 0 recrutamento ministerial, $1850-2000$. Lisboa: Imprensa de Ciências Sociais, 2006. p. 59-136.

LOBO, Marina C. A elite partidária em Portugal, 1976-2002: dirigentes, deputados e membros do governo. In: PINTO, António C.; FREIRE, André (Eds.). Elites, sociedade e mudança política. Oeiras: Celta, 2003. p. 249-275.

NÓVOA, António. The restructuring of the European educational space. In: POPKEWITZ, Thomas (Ed.). Educational knowledge: changing relationships between the state, civil society, and the educational community. New York: State University of the New York Press, 2000, p. 31-57.

NÓVOA, António; SANTA-CLARA, Ana T. (Eds.). Liceus de Portugal: histórias, arquivos e memória. Porto: Asa, 2003.

PANEBIANCO, Angelo. Political parties: organization and power. Cambridge: CUP, 1988.

PETITAT, André. Production de l'école, production de la societé. Genebra: Droz, 1982.

PINTO, António C. 0 império do professor: Salazar e a elite ministerial do Estado Novo (1933-1945). Análise Social, Lisboa, v. 35 , n. 157, p. 1-22, 2000.

PINTO, António C.; ALMEIDA, Pedro T. Portugal: the primacy of "independentes". In: DOWING, Keith; DUMONT, Patrick (Eds.). The selection of ministers in Europe: hiring and firing. Londres: Routledge, 2009.

POPKEWITZ, Thomas. Sociología política de las reformas educativas: el poder/saber en la enseñanza, la formación del profesorado y la investigación. Madrid: Morata, 1991.

POPKEWITZ, Thomas. Cosmopolitanism and the age of school reform: science, education, and making society by making the child. New York: Routledge, 2008.

PUJADAS, Juan. El método biográfico: el uso de las historias de vida en ciencias sociales. Madrid: CIS, 1992.

SAVAGE, Mike; WILLIAMS, Karel (Eds.). Remembering elites. Malden: Blackwell, 2008.

SEDAS NUNES, Adérito. Portugal: sociedade dualista em evolução. Análise Social, Lisboa, v. 2, n. 7-8, p. 407-462, 1964.

SOTIROPOULOS, Dimitri; BOURIKOS, Dimitris. A elite ministerial da Grécia, 1843-2001. In: ALMEIDA, Pedro T.; PINTO, António C.; BERMEO, Nancy (Eds.). Quem governa a Europa do Sul?: 0 recrutamento ministerial, 1850-2000, Lisboa: Imprensa de Ciências Sociais, 2006. p. 175-230.

TEODORO, António. As políticas de educação em discurso directo (1955-95). Lisboa: IIE, 2002.

TEODORO, António; ANÍBAL, Graça. A educação em tempos de globalização: modernização e hibridismo nas políticas educativas em Portugal. Revista Lusófona de Educação, Lisboa, n. 10, p. 13-26, 2007.

WAGNER, Anne-Catherine. Les classes sociales dans la mondialisation. Paris: La Découverte, 2007.

WARREN, Mark; Mapp, Karen. A match on dry grass: community organizing as a catalyst for school reform. New York: Oxford University Press, 2011.

WEBER, Max. Economy and society: an outline of interpretive sociology. New York: Bedminster Press, 1968.

WRIGHT MILLS, Charles. The power elite. Oxford: Oxford University Press, 1959.

Recebido em: 03.04.2013

Aprovado em: 30.09.2013

Pedro Abrantes é professor auxiliar de sociologia na Universidade Aberta e membro do Centro de Investigação e Estudos de Sociologia do ISCTE - Instituto Universitário de Lisboa, onde tem participado em diversas pesquisas nacionais e internacionais, nas áreas da educação, juventude e desigualdades.

Cristina Roldão é assistente de investigação no Centro de Investigação e Estudos de Sociologia (CIES-IUL) e doutoranda em Sociologia no ISCTE - Instituto Universitário de Lisboa. 